BLS 35, No 2 2009. DOI: http://dx.doi.org/10.3765/bls.v35i2.3508

(published by the Berkeley Linguistics Society and the Linguistic Society of America)

\title{
Nepali Sign Language and Nepali: Social and Linguistic Dimensions of a Case of Inter-Modal Language Contact*
}

\author{
E. MARA GREEN \\ University of California, Berkeley
}

\section{Introduction}

In this paper, I examine inter-modal language contact between Nepali Sign Language (NSL) and Nepali, focusing particularly on the semantic domain of kinship. As one aspect of an on-going research project, this paper draws on five months of preliminary fieldwork with deaf communities and individuals in Nepal. ${ }^{1}$ In the original paper presented at BLS 35, I showed how NSL, which developed in the last few decades in a primarily Nepali-speaking environment, exploits modality-specific resources in its systematic replication of the Nepali language kinship domain. I argued that in light of the data, we should rethink either Winford's (2003) implicational constraints on lexical and structural borrowing and/or how the term 'borrowing' makes presumptions about sociallinguistic relationships that do not necessarily apply to (at least this) signed language. While maintaining the original empirical and theoretical material, the current version also incorporates new ideas that have arisen from the process of presenting, receiving feedback on, and rewriting this paper.

\section{Background}

Language contact scholars, like linguists more generally, have concentrated almost exclusively on spoken languages. There are important exceptions to this

\footnotetext{
* I would like to offer my thanks to the many deaf Nepalis who have patiently and generously shared with me their time and language; to the NFDH for its permission to reproduce entries from its dictionary; to Lev Michael and the members of his Fall 2008 language contact seminar, especially Jess Cleary-Kemp for pointing out the sociological inadequacy of the term 'borrowing'; to Erin Wilkinson for so collegially sharing her cross-linguistic data; to Ulrike Zeshan and John Haviland for insightful and provocative comments at BLS; to Elisabeth Wehling, Iksoo Kwan, and Mindi Sue Spike Shepherd for their valuable assistance in preparing the original presentation; to Terra Edwards and Michele Friedner for their excellent suggestions for improving the written version; and to Dristi Shrestha for checking my Nepali script. All errors are obviously my own.

${ }^{1}$ My use of lower-case 'deaf' and the abbreviation NSL both follow the English-language practices of the Nepal National Federation of the Deaf and Hard of Hearing (NFDH).
} 


\section{Nepali Sign Language and Nepali}

trend, and Quinto-Pozos's (2007) introduction to the edited volume Sign Languages in Contact provides a lucid overview of research on contact both between signed and spoken languages (including their written instantiations) and among signed languages. ${ }^{2}$ As he explains, researchers have identified several ways that contact between signed and spoken/written languages manifest in the formermy focus here - such as the appearance of spoken language grammatical features in certain varieties of signed languages, mouthing words while signing, fingerspelling, and 'loan signs' (fingerspelled words with the properties of lexical signs).

During months of fieldwork and language study with deaf Nepalis, I have observed that in some situations or when using certain varieties, signers incorporate Nepali grammatical features, mouth Nepali words, and use the NSL manual alphabet to spell Nepali words (see Green 2002). ${ }^{3}$ Indeed, HoffmannDilloway (2008) writes that hearing teachers of the deaf 'perform standard lexical items in a way that follows ... spoken Nepali' (193), while deaf teachers in deaf organizations sign 'in a manner that is grammatically distinct from spoken Nepali' (ibid) and that 'takes advantage of spatial grammar' (204). ${ }^{4}$ In addition, I propose that NSL evidences what I call 'semantic isomorphism' with Nepali, by which I mean a one-to-one mapping of lexical items in a bounded semantic domain.

Although later in this paper I bring into question the concept of 'borrowing', a traditional analysis of the data would undoubtedly assume that NSL borrowed these items from Nepali, given the languages' socio-historical relationship, briefly detailed below. This claim is not only of potential interest to sign language linguistics, it also bears upon supposedly universal patterns in language contact phenomena. Winford (2003) outlines some of these patterns as a series of implicational constraints, stating that there can be '[n]o structural borrowing without lexical borrowing' (54). In Winford's scheme, phonological, morphological, and syntactic elements are considered structural, while lexical borrowing encompasses borrowing a semantic unit as well as borrowing a phonological form (45). His analysis leaves open the question of whether semantics itself - how a language organizes and expresses meanings - should be considered structural or lexical, a point to which I will return in the final section.

\section{Languages}

Woodward (1993) places Nepali Sign Language in a South Asian sign language family along with Indo-Pakistani Sign Language (see also Zeshan 2003). According to community narratives, NSL has emerged in the last 40 or so years, following the establishment in 1966 of a then-oral school for the deaf in

\footnotetext{
${ }^{2}$ See Boyes Braem and Sutton-Spence (2001), Kegl et al. (1999), Nadolske and Rosenstock (2007), Newport (1999), and Woll (1990), and sources cited in Quinto-Pozos (2007).

${ }^{3}$ Some signers also use the international alphabet (identical to ASL's except for the letter 't') for English words. To the best of my knowledge, NSL does not have 'loan signs.'

${ }^{4}$ Hoffmann-Dilloway's research (Hoffmann 2008 and Hoffmann-Dilloway 2008) examines important linguistic and meta-semiotic aspects of the Nepali-NSL interface. I hope to engage more substantially with this work in the future.
} 


\section{E. Mara Green}

Kathmandu (it now follows a policy of 'total communication'). ${ }^{5}$ Since at least the 1990s, deaf Nepalis have spearheaded efforts at both NSL standardization and outreach (see Green 2007b; Hoffmann-Dilloway 2008), and the Nepal National Federation of the Deaf and Hard of Hearing (NFDH) and the government's 2001 population report claim that there are more than 5000 Nepali Sign Language users. ${ }^{6}$ Nepali, meanwhile, is a member of the Eastern Pahari family of IndoAryan languages. Like its relatives Hindi and Maithili, both spoken in the southern part of Nepal, Nepali is a descendant of Sanskrit. Spoken as a first language by about half of all Nepalis, it is Nepal's official language and the major lingua franca throughout much of the country.

While in the case of most language contact situations (with the obvious exception of new languages like pidgins and creoles) it is possible, at least in theory, to identify what the languages were like 'before contact', NSL emerged in a society already inhabited by Nepali (and other languages). NSL users not only encounter Nepali through speech (intelligible to deaf people in varying degrees) but also through written Nepali and Nepali-dominant signing, whether produced by deaf or hearing people. These three modalities are present in a variety of sites and interactional contexts, including deaf and hearing schools, deaf organizations, vocational training programs, the workplace, the neighborhood, and the home.

\section{Data and Results}

In order to ground the complex phenomenon of NSL-Nepali contact in a relatively bounded field, I turn here to the set of kinship terms given by the NFDH Nepali Sign Language Dictionary, illustrated by the deaf artist Pratigya Shakya. As John Haviland (p.c.) points out, dictionaries are a questionable source for data on actual language use. Indeed, Philip Waters characterizes this particular dictionary as a 'mixed descriptive and prescriptive' document. ${ }^{7}$ Given these methodological and empirical observations, I propose that the dictionary nevertheless represents important conceptions of and claims about the relationship between NSL and Nepali, a point to which I return in the final section.

Each entry in the dictionary includes a drawing of the sign's execution and a Nepali gloss. ${ }^{8}$ Of the 60 entries listed in the section on kinship, I analyzed $56,{ }^{9}$ and found a one-to-one mapping between NSL signs and Nepali words. In nearly all cases, one NSL sign corresponds to exactly one Nepali word, and the sign and the word are co-referential. ${ }^{10}$ Therefore the relationships among the signs, in NSL,

\footnotetext{
5 'Oral' education refers to teaching deaf students to use and understand spoken language to the exclusion of signed language, while total communication includes both signed and spoken practices.

${ }^{6}$ Like other official statistics on language use in Nepal, this one is of questionable precision, but its mere existence, along with published NSL dictionaries, helps to establish deaf signers as a linguistic minority (see Green 2007a, Hoffmann 2008).

${ }^{7} \mathrm{http} / / /$ www.himalayanlanguages.org/?q=team/philip_waters

${ }^{8}$ Each entry also has an English translation, which I do not consider here, but see Green (2007a).

9 I left out 'relatives', 'family', 'old man' and 'old woman': not, strictly speaking, kinship terms.

${ }^{10}$ The sign 'baby/young child' is provided with three Nepali glosses, one each gender-neutral,
} 


\section{Nepali Sign Language and Nepali}

and among the words, in Nepali, are also identical. In this sense the two kinship systems are isomorphic on the level of both the item and the system.

At first glance, this may appear trivial or inevitable, but isomorphic kinship systems are not universal among spoken and signed languages that are used in the same country or region. For example, Adamarobe Sign Language makes fewer lexical distinctions among kinship relations than does Akan (Nyst 2007), while ASL makes one more distinction than English. Massone and Johnson (1991) propose that Argentine Sign Language employs fewer distinct kinship terms than the Spanish that surrounds it because deaf Argentines are less embedded socially in their (biological) kin networks. My preliminary fieldwork strongly suggests that despite language barriers, social prejudices, and an ever-growing deaforiented social network, deaf NSL users are strongly connected to their biological kin networks. For example, while deaf-deaf marriages, including across caste and ethnic lines, seem to be increasing, deaf couples, like other Nepali couples, usually reside with the husband's natal family.

Given that the phonological systems of NSL and Nepali are almost definitionally incompatible, it is of no little interest to consider the formal means through which each language expresses items of and relations within the isomorphic systems. Like all human languages, NSL and Nepali both exhibit arbitrary form-meaning pairings. In addition, the domain of kinship in Nepali is characterized by semi-regular gender marking and extensive sound parallelism between semantically related sets of terms. In NSL, we find highly regular gender marking, visual parallelism, iconicity, and initialization. The examples that follow show how NSL uses both modality-generic and modality-specific strategies to preserve or even emphasize the semantic, and sometimes formal, oppositions and affinities encoded in the Nepali terms.

In example (1), the NSL signs and Nepali words for 'father' and 'mother' are given. ${ }^{11}$ The parts of the signs labeled with the numeral ' 1 ' correspond to the morphemes for 'male' and 'female', while the parts labeled ' 2 ' are a bound morpheme meaning 'parent'. The Nepali words are mono-morphemic, and the NSL signs bi-morphemic, but we can see that the NSL signs, like the Nepali, exhibit formal parallelism. In Nepali, the two words are nearly identical except for the sounds $/ \mathrm{b} /$ and $/(\mathrm{a}) \mathrm{m} /$ which arbitrarily signify the parent's gender, while in NSL the signs' second morpheme is identical.

male-specific, and female-specific, but the NSL gender-marking system can easily combine a gendered marking with 'baby' to produce gender-specific meanings. Several signs are glossed with more than one Nepali equivalent, but the given Nepali words are alternate names for the same kin relationship (much like the English 'grandma', 'grandmother', 'granny'); similarly, the dictionary lists two signs and one Nepali word that mean 'daughter.'

${ }^{11}$ The pictures are from the NFDH dictionary; the first line of text is a morphemic gloss of the NSL; the second is the Nepali gloss in Devanagari script; the third is a spelling-based/ phonological transliteration of the Nepali (since most signers are more familiar with written Nepali than with phonetically detailed speech). The fourth line gives either an English translation or a morphemic gloss of the Nepali; if the latter, then the fifth line gives the English translation of both word and sign. 


\section{E. Mara Green}

(1)

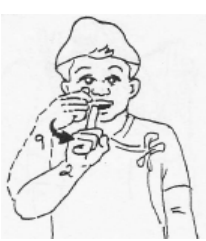

male-parent बा/बुवा

baa/buwaa

'father'

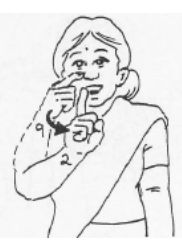

female-parent आमा/मुवा

aamaa/muwaa

'mother'

Of the 56 NSL terms included in this study, 54 of them overtly mark gender, and of these, the gender morpheme occurs first in 50, as in the example above. With the exception of the sign 'daughter', which has an alternate form substituting the sign 'girl' for the sign 'female', all 54 gender-marked signs use the gender morphemes shown in example (1). These signs, which also function as unbound morphemes, are examples of metonymic iconicity. The sign 'male' represents a mustache and the sign 'female' represents the nose ring worn by women from some of Nepal's caste and ethnic groups. According to Wilkinson (2008), gender metonymy is common in sign language kinship systems. The NSL pattern of marking gender initially and with a non-simultaneously articulated, unbound morpheme is thus unusual, at least in relation to Wilkinson's cross-linguistic data.

In contrast to NSL, Nepali uses several different ways to mark gender. The most common, occurring in 15 pairs of words, places the morpheme $-i$ (or one of its allomorphs $-n i$, -ani) word-finally, sometimes replacing the final vowel of the malegendered word. Examples include naati 'grandson' and naatini 'granddaughter', as well as kaakaa 'father's younger brother' and kaaki 'wife of father's younger brother'. Other related pairs use a bound, gender-neutral honorific morpheme on either the male or the female. Consider phupaajyu ${ }^{12}$ 'husband of father's sister' and phupu 'father's sister', but maamaa 'mother's brother' and maaijyu 'wife of mother's brother.' There are also terms such as sasuraa 'father-in-law' and saasu 'mother-in-law' that use sound parallelism to mark the semantic relationship, and sound difference (but not an identifiable morpheme) to mark gender. Due to these variations, it is difficult for me to say how many Nepali terms formally mark gender, but the number appears to be close or equal to the NSL number. Thus in terms of gender marking, NSL differs from the Nepali primarily in the position of the gender marker and in the former's use of metonymic iconicity.

It is now worth returning to those NSL signs in which gender is not marked signinitially. Example (2) shows two of the four signs. The first morphemes, labeled with the numerals 1 and 2, are articulated with a closed hand opening up, that is, getting larger. The second and third morphemes, labeled 3 and 4 (the Nepali ' 4 ' looks like an

${ }^{12}$ Following one of several semi-standard orthographic systems for transliterating Nepali, a consonant followed by the letter ' $h$ ' represents a single aspirated phoneme. 


\section{Nepali Sign Language and Nepali}

upside-down ribbon), are 'male' or 'female' and 'parent'. These signs literally translate as 'big father' and 'big mother', exact calques of the literal Nepali meanings.

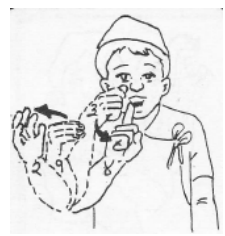

male-parent-big

ठूला बा

Thulaa baa ${ }^{13}$ (lit. 'big father')

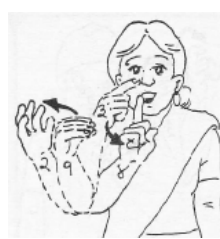

female-parent-big ठूली आमा

Thuli aamaa (lit. 'big mother')

'father's older brother's wife'

Nepali also has a pair of words that literally translate as 'small father' and 'small mother', which NSL also calques. These four signs are the only ones that include the gender morpheme in non-initial position, which renders the calque exact. These are also the only Nepali kin terms that include a word from another semantic domain (size), and, perhaps not coincidentally, this domain is easily represented visually.

In addition to gender, absolute age, relative age and status are also encoded iconically in NSL. Example (3) demonstrates how the NSL signs for 'grandfather' and 'grandmother' express old age as central to the concept of 'grandparent', with the bent shape of the index finger representing the posture of an old man or woman. Indeed, the signs for 'old man' and 'grandfather' and 'old woman' and 'grandmother' are essentially identical ${ }^{14}$ (the Nepali words are not). In the Nepali alternatives, 'old age' is either implicit in the spoken forms as part of the semantics, or indirectly expressed with the honorific hajur, which is applied to people with high status, often associated with old age.

(3)

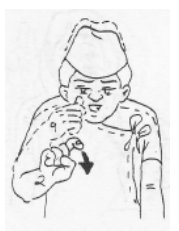

male-old.person

बाजे/हजुरबा

baaje/hajur.baa

'grandfather'

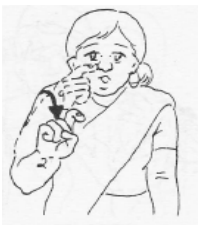

female-old.person बज्यै/हजुरआमा

bajyai/hajur.aamaa

'grandmother'

\footnotetext{
${ }^{13}$ Capital letters represent retroflex consonants; followed by ' $h$ ' they represent retroflex aspirated.

${ }^{14}$ To illustrate this, I have used the drawing for the sign 'old man' on the left and the drawing for the sign 'grandmother' on the right. The dotted lines in the former show that the signer also hunches the shoulders; this sign is a real-space blend in which shoulders and index finger both represent an old man's posture, but in different scales (see Dudis 2004). It remains to be studied whether hunching is obligatory for and exclusive to the sign 'old person'.
} 


\section{E. Mara Green}

In (4), relative age is also represented iconically. The Nepali jeThaa 'eldest male sibling' and jeThi 'eldest female sibling' are two of the widely used Nepali dyads that identify the age rank of one's children, brothers and sisters, acquaintances, or self, in relation to siblings of the same sex. While in Nepali the age rank is a semantic, but not formal, dimension, in NSL age rank is formally expressed with a separate morpheme.

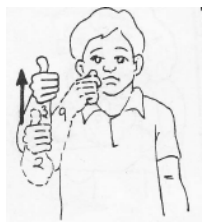

male-first

जेठा

jeThaa

'eldest male sibling'

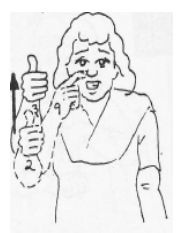

female-first

जेठी

jeThi

'oldest female sibling'

The rest of the semantic set - 'second oldest male sibling', 'second oldest female sibling', etc. - follow this formal pattern. For 'second', 'third', and 'fourth', the appropriate number of fingers (including the thumb) extend on the non-dominant hand and the dominant hand grasps the non-dominant hand's relevant finger (the second, third, or fourth, counting down from the thumb). The sign for the 'youngest' is made similarly to the sign in example (4) but with only pinky finger extended and the hand moving downwards. This setting-off of the 'eldest' and 'youngest' terms from the rest also exhibits formal parallelism with the Nepali. The Nepali words for the second, third, and fourth oldest male and female siblings rhyme (maailo, maaili; saailo, saaili; kaailo, kaaili ${ }^{15}$ ) while the words for the youngest ones (kaanchha, kaanchhi), like the words for the oldest, are distinct.

Relative age-rank is also encoded by the terms for brother and sister, of which there are four in both Nepali and NSL, as shown in (5). ${ }^{16}$ This table shows that there are two axes of opposition, gender and relative age. For Nepali, gendered pairs are linked through word endings: $-i$ for female and -aai for male. Age pairs are linked through their initial sounds. The older sibling terms didi 'older sister' and daai 'older brother' start with the same consonant. The younger sibling terms bahini 'younger sister' and bhaai 'younger brother', on the other hand, begin with different phonemes (and letters), but as the transliteration indicates, the sounds are phonetically similar and much more similar to each other than either is to the sound with which didi and daai begin.

${ }^{15}$ The initial diphthongs in saailo, saaili, kaailo, and kaaili are nasalized, but this does not diminish the strong sound parallel with maailo, maaili.

${ }^{16}$ In practice NSL users commonly combine the two systems to list siblings by touching in descending order the fingers of the non-dominant hand and signing daai 'elder brother', didi 'elder sister,' bhaai 'younger brother' or bahini 'younger sister' in turn to demonstrate whether each sibling is male or female as well as older or younger in relation to the signer. 


\section{Nepali Sign Language and Nepali}

(5)

\begin{tabular}{|l|l|l|l|}
\hline Nepali and NSL Siblings & Female & Male \\
\hline Younger & $\begin{array}{l}\text { बहिनी } \\
\text { bahini }\end{array}$ & $\begin{array}{l}\text { भाइ } \\
\text { bhaai }\end{array}$ \\
\hline Older & $\begin{array}{l}\text { दिदी } \\
\text { didi }\end{array}$ & $\begin{array}{l}\text { दाई } \\
\text { daai }\end{array}$ \\
\hline
\end{tabular}

In NSL, meanwhile, the gendered pairs are linked through the initial morpheme, while the age pairs are linked through the final morpheme. The final morpheme is an iconic representation of height, metaphorically standing in for relative age. Thus the NSL terms preserve both the gender and age pairings of the Nepali, emphasizing the latter through metaphoric iconicity.

As mentioned previously, age in Nepal(i) is closely linked with status. In Nepali, status is nearly always an implicit semantic aspect of the kinship term, except in cases like example (3) that incorporate an honorific. In NSL, status is rendered visible through the location of the hands, as shown in (6). ${ }^{17}$

(6)

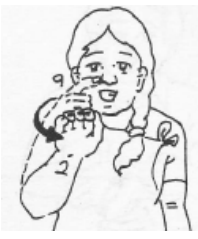

female-SA

सासु

saasu

'mother-in-law'

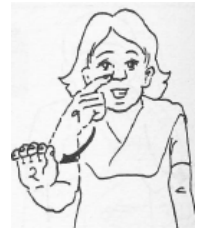

female-SA

साली

saali

'wife's younger sister'

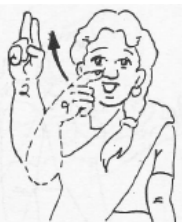

female-BHA

भाउजू

bhaauju

'older brother's wife'

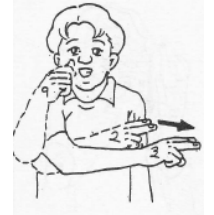

male-BHA

भान्जा

bhaanjaa

'sister's son'

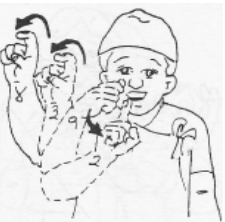

male-parent-old.person-old.person जिजुबा

jijubaa

'great-grandfather'

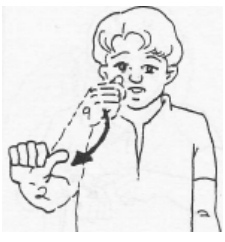

male-JA

ज्वाई

jwaai

'younger sister's husband'

${ }^{17} \mathrm{SA}, \mathrm{BHA}$, and JA are examples of initialization, discussed shortly. 


\section{E. Mara Green}

The first row of signs are higher in status than ego, while the second row are lower in status than ego. For each, the status corresponds to the height or location of the second morpheme. This height is not gradient, but categorical. That is to say, the sign for 'father-in-law', at least as drawn here, articulates the second morpheme at a lower level than does the sign for 'older brother's wife.' This does not mean that the former has lower status than the latter in relation to ego. Rather, signs articulated above the shoulder line are high status, and those at the chest level are low status. The first sign from each row together demonstrate that the height/location distinguishes members of a minimal pair.

Now let me turn to another way that NSL links signs both to each other and to Nepali, shown in (6) and more fully demonstrated in (7). A subset of NSL kin terms employ alphabetic characters from the NSL manual alphabet, which is based on the Nepali writing system. Initialization is a common, though not universal, phenomenon in sign language kinship terms (Wilkinson 2008).

(7)

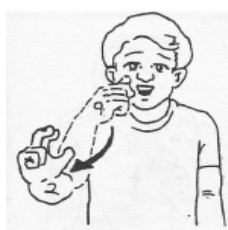

male-DA

देवर

dewar

'husband's younger brother'

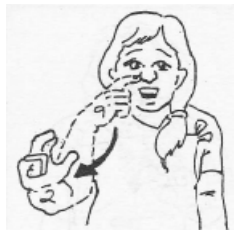

female-DA

देवरानी

dewaraani

In (7), the Nepali pair of terms is linked through sound, the morpheme dewar being present in both words. In NSL, the pair is linked through the second morpheme, which is the manual sign for the character द (da). ${ }^{18}$ Like the exact calque in example (2), but even more explicitly, initialization uses languagespecific resources (here, the manual alphabet) to reference another language. One need not know Nepali to understand the meanings of initialized terms, yet the use of fingerspelling in other contexts continually reinforces the relationship between the NSL and Nepali terms. As elsewhere, we also see that NSL preserves both the gender distinction and the formal parallel present in the Nepali dyad.

Out of 56 total terms, 22 use initialization. In addition there are two signs that I had tentatively analyzed as a case of productive but 'faux' initialization. These signs - phupajyu 'father's sister's husband' and phupu 'father's sister' - look similar in form to the 22 real initialized signs, but the manual alphabet character used, ण (na) does not correspond to the Nepali words, which begin with फ (pha). Ulrike Zeshan (p.c.) points out that these two signs are formally and semantically

${ }^{18}$ In Nepali script, the consonants 'come with' a vowel, transliterated as a single [a]. Thus the manual alphabet character [द] (da) that NSL uses for dewar does not correspond exactly to the written form [दे] (de). John Sylak (p.c.) suggests that we think of this as phonological reduction. 


\section{Nepali Sign Language and Nepali}

identical to ones in IPSL. She also observes that there are other kin term cognates in NSL and IPSL. This raises important questions regarding the historical development of South Asian sign languages, intra-modal sign language contact, and the meta-pragmatics of language contact. The first two are beyond the scope of this paper, while the last is a point I raised above and to which I return below.

\section{Conclusion and Discussion}

Despite incompatible phonological systems, the NSL kinship system is isomorphic with that of Nepali. Nepali and NSL both express individual items and relations between items using modality-generic resources such as arbitrary formmeaning mapping and gender-marking. Nepali uses the modality-specific resource of sound parallels. Meanwhile, NSL makes use of modality-specific resources such as visual iconicity (including metaphoric iconicity) and initialization to produce and even emphasize semantic connections and oppositions, as well as to maintain some of the formal relationships present in the Nepali.

The data and my analysis of it lead to several possible conclusions. First, in accordance with Winford's proposed universal implicational restraints, we note that the set of semantic calques discussed in example (2) constitutes an instance of lexical borrowing. As mentioned earlier, Winford does not address whether what I have called semantic isomorphism should be counted as lexical or structural borrowing. I argue here that the one-to-one mapping of Nepali and NSL kinship terms is indeed structural, since the inter-relations of kinship terms are systematic in the same sense that phonological, morphological, and syntactic patterns are systematic. ${ }^{19}$ At the same time, my focus on kinship raises the question of whether implicational constraints must be assessed from the point of an 'entire' language or whether they might also hold within restricted semantic domains. If we consider only the restricted domain, it becomes critical that in the NSL-Nepali case, the presence of the semantic calques appears entirely incidental to the borrowing of the kinship system itself, especially when we remember that the only Nepali terms calqued are those that include morphemes from the domain of size. Since the analytic force of implicational constraints assumes that the patterns they capture are not epiphenomenal, this raises the possibility that Winford's constraints might not be universally applicable. More broadly, my paper suggests the importance of further research on inter-modal language contact and of the incorporation of signed-signed and signed-spoken language contact data into formulations of language universals. It also demonstrates the potential productivity of investigating how languages in contact draw on each others' systems of meaning. It would be interesting, for example, to examine how semantic structure interacts with more 'traditional' categories of linguistic structure in the realm of language contact phenomena.

A second different set of conclusions arises if we consider more carefully the sociological aspects of NSL and Nepali contact. NSL arose in a milieu saturated

\footnotetext{
${ }^{19}$ This point has been observed and explored by the great structuralists of the early $20^{\text {th }}$ century.
} 


\section{E. Mara Green}

with spoken and written Nepali, and NSL's first and subsequent users - however we understand the always problematic nature of the language's 'origins' developed their language as members, albeit marginalized ones, of the broader society. In this sense it would be inaccurate to say that NSL 'borrowed' the kinship distinctions encoded by Nepali, even though the former in some sense reproduces the latter. Extrapolating from this point, it seems that, as with other aspects of linguistic theory, research on deaf societies and signed languages asks us to refine and reformulate the concept of language contact, and forces us to pay ever closer attention to the interplay between social processes and linguistic structure.

Finally, following the tradition of meta-pragmatic research that can be traced to Silverstein (1976) among other seminal works, this paper illustrates that in conceptualizing the relationships between languages, people are as interested in sociality as in what linguists would call historical or linguistic relationships. That is to say, what the creators of the NSL dictionary found relevant was how NSL and Nepali map onto each other, and not, for example, the relationship between NSL and IPSL or NSL and any other of Nepal's spoken languages. Indeed the dictionary itself - not only encountered as a visible icon of the deaf social movement in Nepal but also found, dog-eared and worn, in so many deaf people's homes - and especially its representation of the domain of kinship present a particular vision of NSL, and likewise its users, as members of the Nepali family.

\section{References}

Boyes Braem, Penny, and Rachel Sutton-Spence, eds. 2001. The hands are the head of the mouth: The mouth as articulator in sign languages. Hamburg: Signum Verlag.

Dudis, Paul. 2004. Body partitioning and real-space blends. Cognitive Linguistics 15(2):223-238

Green, E. Mara. 2002. Hands that speak: An ethnography of deafness in Nepal. B.A. thesis, Amherst College.

Green, E. Mara. 2007a. The social life of dictionaries. Ms., University of California, Berkeley.

Green, E. Mara. 2007b. Slippery like a fish: Community, ownership, and Nepali Sign Language. Paper presented at Center for Race and Gender, University of California, Berkeley.

Hoffmann, Erika. 2008. Standardization beyond form: Ideologies, institutions, and the semiotics of Nepali Sign Language. Ph.D. diss., University of Michigan.

Hoffman-Dilloway, Erika. 2008. Metasemiotic regimentation in the standardization of Nepali Sign Language. Journal of Linguistic Anthropology 18(2):192-213. 


\section{Nepali Sign Language and Nepali}

Kegl, Judy, Ann Senghas, and Marie Coppola. 1999. Creation through contact: Sign language emergence and sign language change in Nicaragua. In Michel DeGraff, ed., Language creation and language change: Creolization, diachrony, and development, 179-237. Cambridge, MA: MIT Press.

Massone, Maria Ignacia, and Robert E. Johnson. 1991. Kinship terms in Argentine Sign Language. Sign Language Studies 73:347-360.

Nadolske, Marie, and Rachel Rosenstock. 2007. Occurrence of mouthings in American Sign Language: a preliminary study. In P. Perniss, R. Pfau, and M. Steinbach, eds., Visible variation: Comparative studies on sign language structure, 35-62. Berlin: de Gruyter.

Nepali Sign Language Dictionary. 1996. Kathmandu, Nepal: Nepal National Federation of the Deaf and Hard of Hearing.

Newport, Elissa L. 1999. Reduced input in the scquisition of signed languages: contributions to the study of creolization. In Michel DeGraff, ed., Language creation and language change: Creolization, diachrony, and development, 161-178. Cambridge, MA: MIT Press.

Nyst, Victoria. 2007. A descriptive analysis of Adamorobe Sign Language (Ghana). LOT Dissertation Series 151. Utrecht: Landelijke Onderzoekschool Taalwetenschap.

Quinto-Pozos, David, ed. 2007. Sign languages in contact. Washington DC: Gallaudet University Press.

Silverstein, Michael. 1976. Shifters, linguistic categories, and cultural description. In Keith H. Basso and Henry A. Selby, eds., Meaning in anthropology, 11-55. Albuquerque: University of New Mexico Press.

Wilkinson, Erin Laine. 2008. Typology of signed languages: Differentiation through kinship terminology. Diss. proposal, University of New Mexico.

Winford, Donald. 2003. An introduction to contact linguistics. Malden, MA: Blackwell Publishing.

Woll, Bencie. 1990. International perspectives on sign language communication. International Journal of Sign Linguistics 1(2):107-120.

Woodward, James. 1993. The relationship of sign language varieties in India, Pakistan, and Nepal. Sign Language Studies 78:15-22.

Zeshan, Ulrike. 2003. Indo-Pakistani Sign Language grammar: A typological outline. Sign Language Studies 3(2):157-212.

E. Mara Green

University of California, Berkeley

Department of Anthropology

232 Kroeber Hall

Berkeley, CA 94720

emaragreen@berkeley.edu 